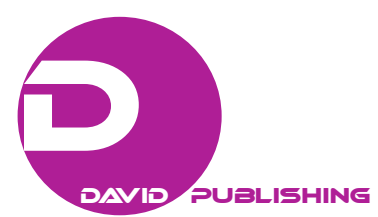

\title{
Multisensory Instruction for Students With Dyscalculia
}

\author{
Vicky Tan Ai Lin, Yeo Kee Jiar \\ Universiti Teknologi Malaysia, Johor Bahru, Malaysia
}

\begin{abstract}
This purpose of this study is to examine the effectiveness of multisensory instruction in enhancing the achievement of a group of primary school students with developmental dyscalculia (DD). A module based on multisensory teaching approach was developed to help the students in solving problems involving subtraction between 0 and 10 using a five-phase ADDIE instructional design. This study answers two research questions: (i) What is the students' achievement level before and after intervention using module based on multisensory approach? (ii) Is there any significant difference before and after intervention using module based on multisensory approach? Quasi-experimental pre-test/post-test design was employed for the present study. Intervention based on the module was carried out for four weeks with 20 sessions of 30 minutes each. Participants include 18 students aged between 10-12 years old from four public schools in Malaysia. Results indicated significant progress with large effect size in acquiring basic subtraction skill. This study revealed that with appropriate teaching method, students with DD are able to succeed in solving mathematics problems involving subtraction.
\end{abstract}

Keywords: mathematics learning difficulties, developmental dyscalculia, subtraction, multisensory teaching approach, module, intervention

\section{Introduction}

DD is an innate learning difficulty in understanding arithmetical concepts (Cappelletti \& Price, 2014). According to Peard (2010), DD is the consequences of precise infirmities in dealing with elementary arithmetical calculation rather than the result of shortfalls in other cognitive capabilities. Scholars have yet to apprehend the roots of dyscalculia (Zerafa, 2011). However they believe that neurological source might be one of the numerous (Rapin, 2016). Dyscalculia is a severe learning malady and not a petty "hiccup” in learning mathematics that can be effortlessly fixed or glossed over (Ranpura, Isaacs, Edmonds, Rogers, Lanigan, Singhal, \& Butterworth, 2013). Past studies revealed that dyscalculia affects 3.5\%-6.5\% of school-age children (Wang, Qin, Chang, \& Zhu, 2015). Unfortunately it did not receive much investigation (Von Aster \& Shalev, 2007). In spite of high occurrence rates of DD, research about the neurocognitive and developmental characteristics of this learning disability is sparse (Wang et al., 2015). Most experts believe dyscalculia is not wholly surveyed in comparison with other learning disability (Rapin, 2016; Kazemi, Momeni, \& Abolghasemi, 2014). This research is important because to the best knowledge of the researcher there is no module specially developed for students with DD in learning subtraction for numbers 0-10 particularly in the four schools

Vicky Tan Ai Lin, Ph.D. student, Universiti Teknologi Malaysia, Johor Bahru, Malaysia.

Yeo Kee Jiar, Ph.D., associate professor, Universiti Teknologi Malaysia, Johor Bahru, Malaysia.

Correspondence concerning this article should be addressed to Vicky Tan Ai Lin, Faculty of Education, Universiti Teknologi Malaysia, Johor Bahru 81310, Johor, Malaysia. 
involved in this study. Therefore this paper puts forth the argument that there is a need of using appropriate approach in helping children with DD. The present study investigates the effectiveness of a module based on multisensory teaching approach using math manipulatives and visual aids (video) in enhancing the performance of students struggling solving problems involving subtraction.

\section{DD and Multisensory Teaching Approach}

The utmost agreed characteristic of students with dyscalculia is difficulty in learning and recalling mathematics actualities (Kazemi et al., 2014). Dyscalculic learners have "no sense for numbers", deprived capability in evaluating and unable to recognize if a solution to a mathematical chore is rational or not (Bird, 2009). Multisensory approach combines auditory, visual, and kinesthetic learning styles. Every instructional lesson is designed to use two or more modalities (Obradovi, Bjeki, \& Zlati, 2015). Knowledge learned through all the senses is beneficial in strengthening memory and this idea has an extensive antiquity in pedagogy (Jubran, 2011). Abstract concepts in Mathematics need to bring to the concrete level for better understanding (Obaid, 2013). Using multisensory teaching approaches for students with significant disabilities in mathematics will provide an opportunity for them to use more than one sense to gain a skill or concept in multiple and varying lessons (Aydemir, 2015).

\section{Methodology}

This study was conducted based on the five-phase ADDIE instructional design framework namely analysis, design, development, implementation, and evaluation. Eighteen primary level school children stressed with mathematics aged 10 to 12 years old from the district of Johor Bahru, Malaysia were chosen as participants in this study. These students were chosen from four primary schools in convenient sampling methods which were used to select participants. The Dyscalculia Screener (Butterworth, 2003) was governed to all these students. Pretest was administered to ensure that there are no significant differences between participants in terms of individualities like age and knowledge progress. One group quasi-experimental pre-test/post-test design was used for this study. Pre-test was administered three weeks before the intervention. A multisensory module was developed to teach subtraction skills to these participants. An intervention using multisensory teaching module was implemented for four weeks, 30 minutes each session 5 times a week. After four weeks of intervention, post-test was then carried out. A self-design mathematics test with a total number of 10 items was administered before and after the intervention to assess the performance of the students in solving problems involving subtraction for number from 0 to 10 .

\section{Results and Finding}

The test results were analyzed using Rasch Measurement analysis and SPSS involving Wilcoxon signed-rank test. Table 1 shows the item fit analysis. Item fit is an index of item's quality and construct consistency to respondents. A misfit in an item may reflect that the item is too complex, confusing or it measures a different construct (Linacre, 2012). The outfit statistics, infit statistics, and Rasch reliability were also applied to examine the quality of the measure from a Rasch measurement perception. Both outfit and infit mean square errors (MNSQ) are measures to evaluate the fitness of data according to the stipulations of Rasch model. Outfit and infit MNSQ can take the values from 0 to positive infinity but the ultimate value is 1.0 which means the data match the Rasch model flawlessly (Linacre, 2012). Bond and Fox (2007) considered 0.6 to 1.4 
as an acceptable infit MNSQ range while Linacre (2012) recommended 0.5 to 1.5 for productive measurement. This study adopted Bond and Fox's values of MNSQ dwindling in the span of 0.6 to 1.4 to designate a satisfactory indication of good fit between data and model.

Table 1

Item Fit Analysis

\begin{tabular}{lllll}
\hline \multirow{2}{*}{ Item } & \multicolumn{2}{c}{ Infit } & Outfit \\
\cline { 2 - 5 } & MNSQ & ZSTD & MNSQ & ZSTD \\
\hline Q7 & 1.37 & 1.6 & 1.34 & 1.0 \\
Q9 & 1.27 & 0.7 & 0.96 & 0.2 \\
Q8 & 1.28 & 1.1 & 1.18 & 0.5 \\
Q10 & -0.2 & 1.25 & 1.5 \\
Q5 & 0.85 & 0.5 & 1.00 & 0.2 \\
Q6 & 1.13 & -0.5 & 0.65 & -0.3 \\
Q4 & 0.83 & -1.1 & 0.66 & -1.0 \\
Q1 & 0.67 & 0.1 & 0.65 & -0.1 \\
Q2 & 0.81 & 0.2 & 0.65 & -0.1 \\
Q3 & 0.81 & -1.8 & 0.63 & -0.8 \\
\hline
\end{tabular}

Referring to Table 1, the infit MNSQ value is in the span of 0.66 and 1.37, while the outfit MNSQ is in the span of 0.63 and 1.34. All the infit and outfit MNSQ figures are within the range suggested by Bond and Fox (2007). This implies that all items align with the person abilities. Table 2 shows the item polarity. Polarities of items can be determined through the Point-measure Correlation (PTMEA CORR.). Nunnally and Bernstein (1994) suggest that the PTMEA value CORR. for questions is to be exceeding 0.30 .

Table 2

Item Polarity

\begin{tabular}{ll}
\hline Item & PTMEA CORR. \\
\hline Q7 & 0.46 \\
Q9 & 0.51 \\
Q8 & 0.52 \\
Q10 & 0.54 \\
Q5 & 0.55 \\
Q6 & 0.67 \\
Q4 & 0.69 \\
Q1 & 0.74 \\
Q2 & 0.74 \\
Q3 & 0.74 \\
\hline
\end{tabular}

Based on Table 2, all 10 items exceed 0.30 as suggested by Nunnally and Bernstein (1994) and have positive point measure correlation (PT-MEASURE CORR.), in the range of 0.46 to 0.74 . This implies the adequacy of items to measure what was supposed to measure and also indicated that the item estimates would be replicative in a similar sample. Table 3 shows the item difficulty level for pre- and post-test. 
Table 3

Item Difficulty Level

\begin{tabular}{llll}
\hline Pre-test & & Post-test & \\
\hline Question & Logit & Question & Logit \\
\hline Q4 & 1.64 & Q9 & 1.62 \\
Q5 & 1.64 & Q10 & 1.62 \\
Q9 & 1.64 & Q5 & 0.71 \\
Q10 & 1.64 & Q4 & -0.10 \\
Q3 & -0.22 & Q8 & -0.10 \\
Q8 & -0.22 & Q6 & -0.91 \\
Q6 & -1.02 & Q7 & -0.91 \\
Q7 & -1.02 & Q3 & -1.94 \\
Q1 & -2.04 & Q1 & -3.34 \\
Q2 & -2.04 & Q2 & -3.34 \\
\hline
\end{tabular}

With reference to Table 3, the level of difficulty for pre-test is in the range between -2.04 until 1.64 logit. The most difficult question in pre-test was Q4 (1.64 logit) while the easiest was Q6 (-2.04 logit). After the intervention, the level of difficulties decreased to the range from -3.34 to 1.62 logit. The most difficult question in post-test was Q9 (1.62) while the easiest question was Q2 (-3.34 logit).

\section{Difference Between Pre- and Post-tests Results}

Students' levels of achievement were categorized into three: low, intermediate, and high level. Figure 1 shows the number of students in low, intermediate, and high level during pre- and post-test. All 18 students (100\%) were in low achievement level during pre-test. No students are in the intermediate or in high level. However after the intervention, students made significant progress. Sixteen students (88.89\%) were in high level and two students (11.11\%) were in intermediate level while none in low level as shown in Figure 1.

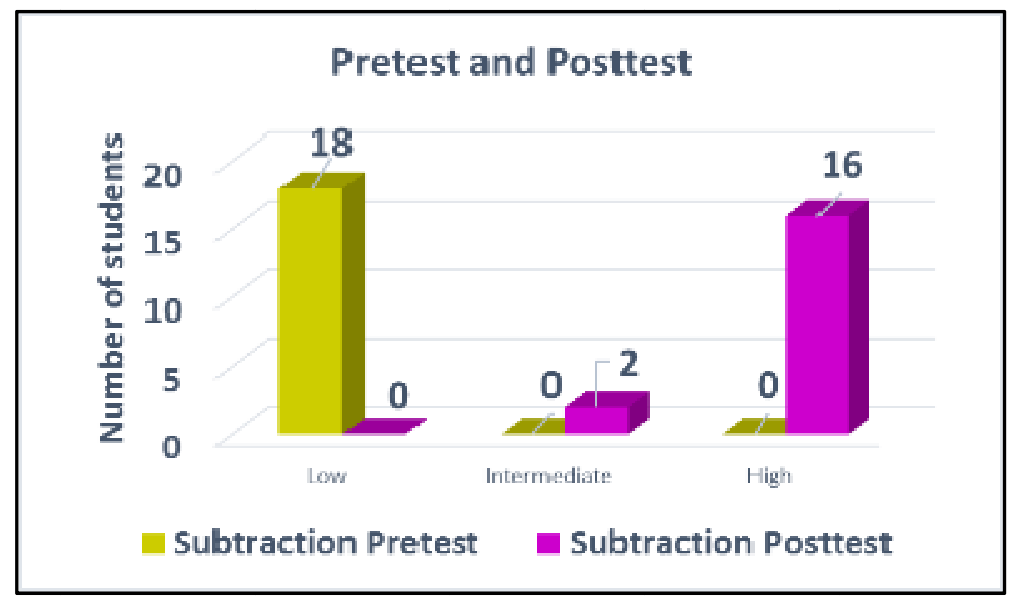

Figure 1. Level of achievement.

The mean score was 0.28 ( $\mathrm{SD}=0.669)$ before the intervention. After four weeks of intervention, mean score rose to $8.56(\mathrm{SD}=1.504)$. The minimum score during pre-test was 0 while the maximum score was two. After the intervention, the minimum score for post-test was five while the maximum score was 10 . Table 4 shows the Wilcoxon signed-rank test analysis between pre- and post-test. In subtraction, effect sizes were reported to demonstrate the magnitude of the intervention effect. 
Table 4

Wilcoxon Signed-Rank Test Analysis Between Pre- and Post-test

\begin{tabular}{llllll}
\hline Time & Pre-test & Post-test & Z-value & $p$-value & $\begin{array}{l}\text { Effect size } \\
(r)\end{array}$ \\
\hline $\mathrm{N}$ & 18 & 18 & & & \\
Mean (M) & 0.50 & 9.28 & $\mathrm{Z}=-3.767$ & $p=* 0.000$ & $r=0.87$ \\
Standard deviation (SD) & 0.857 & 0.958 & & & \\
\hline
\end{tabular}

Based on Table 4, $p<0.05$, illustrates noteworthy variance between pre- and post-test. Mean score after intervention, 9.28 is greater than the mean score before intervention (0.50) with large effect size $(r=0.87)$. This indicates that multisensory teaching module using concrete materials and video is effective in teaching subtraction to children with dyscalculia. This result shows that multisensory teaching module using math manipulatives and visual aids led to an increase in mathematics achievement involving subtraction among dyscalculia students.

\section{Discussion}

The progress made by the students is an indicator that multisensory teaching module used in this study is efficient. The obtained results emphasize that children with DD have the potential of making significant progress provided that they follow an intensive, daily learning programme adjusted to their own needs, strengths, and weaknesses. It underscores the importance of multisensory learning principles so that learning is associated with pleasure and enjoyment. This study corroborates the idea of Ryan and Deci (2000), who suggest that teachers should attempt to make learning as intrinsically interesting as possible. The findings from the study imply that appropriate intervention is one which can provide teachers with pedagogical content knowledge on early mathematics instruction and offer teachers professional development on the instructional strategies. Appropriate intervention should have a systematically organized learning content followed by simple to complex progression.

\section{Conclusion}

Multisensory teaching module using math manipulatives and visual aids proves to be beneficial to students with dyscalculia in learning subtraction. Given the complex challenges of teaching mathematics effectively it begs the question whether conventional teaching methods are sufficient to meet the needs of students with dyscalculia in learning mathematics. However the conclusion of this study is limited by small sample of participants and in solving subtraction problems namely for numbers from 0 to 10 only. It is proposed to implement the findings of this study to larger sample sizes and control group.

\section{References}

Aydemir, T. (2015). A review of the articles about TouchMath. 174, 1812-1819. http://doi.org/10.1016/j.sbspro.2015.01.842

Bond, T. G., \& Fox, C. M. (2007). Applying the Rasch model: Fundamental measurement in the human sciences (2nd ed.). New Jersey: Lawrence Erlbaum Associates.

Bird, R. (2009). Overcoming difficulties with number: Supporting dyscalculia and students who struggle with maths. London: Sage Publication.

Butterworth, B. (2003). Dyscalculia screener: Highlighting children with specific learning difficulties in mathematics. London: NFER-Nelson.

Cappelletti, M., \& Price, C. J. (2014). Residual number processing in dyscalculia. NeuroImage: Clinical, 4, $18-28$. http://doi.org/10.1016/j.nicl.2013.10.004 
Jubran, S. (2011). Using multi-sensory approach for teaching English skills and its effect on students' achievement at Jordanian schools. European Scientific Journal, 8(22), ISSN: 1857-7881 (Print) e-ISSN 1857-7431.

Kazemi, R., Momeni, S., \& Abolghasemi, A. (2014). The effectiveness of life skill training on self-esteem and communication skills of students with dyscalculia. Procedia-Social and Behavioral Sciences, $114, \quad 863-866$. http://doi.org/10.1016/j.sbspro.2013.12.798

Linacre, J. M. (2012). Winsteps \& Rasch measurement computer program user's guide. Beaverton, Oregon: Winsteps.com. Retrieved June 1, 2012, from http://www.winsteps.com

Nunnally, J. C., \& Bernstein, I. H. (1994). Psychometric theory (3rd ed.). New York: McGraw Hill.

Obaid, M. A. S. (2013). The impact of using multi-sensory approach for teaching students with learning disabilities. Journal of International Education Research, 9(1), 75-82.

Obradovi, S., Bjeki, D., \& Zlati, L. (2015). Creative teaching with ICT support for students with specific learning disabilities. International Conference Education and Psychology Challenges-Teachers for the Knowledge Society-3rd ed., Epc-Tks. Procedia-Social and Behavioral Sciences, 203, 291-296.

Peard, R. (2010). Dyscalculia: What is its prevalence? Research evidence from case studies. Procedia-Social and Behavioral Sciences, 8(5), 106-113. http://doi.org/10.1016/j.sbspro.2010.12.015

Ranpura, A., Isaacs, E., Edmonds, C., Rogers, M., Lanigan, J., Singhal, A., \& Butterworth, B. (2013). Developmental trajectories of grey and white matter in dyscalculia. Trends in Neuroscience and Education, 2(2), 56-64. http://doi.org/10.1016/j.tine.2013.06.007

Rapin, I. (2016). Dyscalculia and the calculating brain. Pediatric Neurology. http://doi.org/10.1016/j.pediatrneurol.2016.02.00

Ryan, R. M., \& Deci, E. L. (2000). Self-determination theory and the facilitation of intrinsic motivation, social development and well-being. American Psychologist, 55, 68-78.

Von Aster, M. G., \& Shalev, R. S. (2007). Number development and developmental dyscalculia. Dev. Med. Child Neurol, 49(11), 868-873.

Wang, E., Qin, S., Chang, M., \& Zhu, X. (2015). Digital memory encoding in Chinese dyscalculia: An event-related potential study. Research in Developmental Disabilities, 36, 142-149. http://doi.org/10.1016/j.ridd.2014.09.020

Zerafa, E. (2011). Helping children with dyscalculia: The implementation of a teaching programme with three primary school children. Procedia-Social and Behavioral Sciences, 191, 1178-1182. http://doi.org/10.1016/j.sbspro.2015.04.516 